\title{
Accumulation of compatible solutes in rice (Oryza sativa L.) cultivars by inoculation of endophytic plant growth promoting bacteria to alleviate salt stress
}

\author{
Shamim Ahmed ${ }^{1,4 \dagger}$, Tae-Young Heo ${ }^{2 \dagger}$, Aritra Roy Choudhury ${ }^{1,6}$, Denver I. Walitang ${ }^{1,3}$, Jeongyun Choi ${ }^{1}$ and
} Tongmin $\mathrm{Sa}^{1,5^{*}}$ (D)

\begin{abstract}
Salinization of agricultural lands, particularly rice paddies, results in the drastic decline of crop yields. Soil salinization impacts the plant physiology by inducing salt stress which may leads to osmotic stress, ionic stress and water-related nutrient imbalance. These imbalances necessitate the need for plants to produce osmolytes including proline and glycine betaine. This study aimed to elucidate the dynamic changes in proline and glycine betaine accumulation modulated by the inoculation of Brevibacterium linens RS16 in salt-sensitive and moderately salt-tolerant rice plants under salt stress conditions. This study showed the interaction of four major factors including rice genotypes with differing tolerance to salt stress, length of exposure to salt stress, level of salt stress and effects of inoculation. Salt stress resulted in significant reduction in plant growth parameters with the salt-sensitive rice genotype (IR29) having a more significant growth reduction. Both the salt-sensitive and salt-tolerant rice genotypes increased in total proline and glycine betaine accumulation at 3 days and 10 days after subjecting under $50 \mathrm{mM}$ and $150 \mathrm{mM}$ salt stress conditions. A significant increase in proline and glycine betaine was observed in the salt-sensitive genotype after 10 days under $50 \mathrm{mM}$ and $150 \mathrm{mM}$ salt stress conditions. Inoculation of the rice genotypes with B. linens RS16 resulted in the improvement of plant growth parameters in both rice genotypes, and total proline and glycine betaine accumulation, especially in IR29. This study showed that proline and glycine betaine are compatible osmolytes of rice under salt stress, and that inoculation of rice genotypes with B. linens RS16 mediated salt tolerance through improvement of plant growth parameters and proline and glycine betaine accumulation in rice plants.
\end{abstract}

Keywords: Compatible solutes, Osmolytes, Proline, Glycine betaine, Rice, Solute accumulation

\section{Introduction}

Soil salinization has been affecting agriculture at a greater rate in the recent years. The rise in sea level due to global climate change and the extensive use of chemical

\footnotetext{
*Correspondence: tomsa@chungbuk.ac.kr

†'Shamim Ahmed and Tae-Young Heo contributed equally to this work

1 Present Address: Department of Environmental and Biological

Chemistry, College of Agriculture, Life and Environment Sciences,

Chungbuk National University, Chungbuk 28644 Cheongju, Republic

of Korea

Full list of author information is available at the end of the article
}

fertilizers are the major driving forces of salinization of lands [1]. It has been estimated that around 45 million ha of agricultural lands is affected by salinity [2], an estimated global crop production loss of US\$ 27.3 billion [3]. The high concentration of $\mathrm{Na}^{+}$and $\mathrm{Cl}^{-}$in soil has a detrimental effect on plant physiology, as it restricts nutrient uptake by plants [4]. The higher uptake of $\mathrm{Na}^{+}$by plants causes $\mathrm{K}^{+}$deficiency, disruption in ion homeostasis and dehydration of plant cells [5]. These lead to the reduction in total biomass of plants and eventually in marketable yield. 
Plants produce a wide range of low molecular weight compounds which protect cellular damage against elevated concentration of reactive oxygen species (ROS) [6]. They are also known to play an important role in maintaining the osmotic balance in plants under salt stress [7]. Proline and glycine betaine are two such compatible solutes which belong to the class of amino acid and quaternary ammonium compound (QAC) respectively and play important roles in the maintenance of osmotic balance and alleviation of oxidative stress [8]. Proline accumulation is generally observed in the cytosolic compartment of the plant cells and it plays a significant role in stabilization of cellular membranes, balancing cytosolic acidity, decreasing lipid peroxidation and protection of cellular structures by scavenging ROS [9]. On the other hand, glycine betaine accumulation in plant cells is mostly confined to the sub-cellular compartments like plastids [10]. Glycine betaine also plays a wide range of roles such as sub-cellular membrane stabilization, scavenging of ROS and stabilization of the photosynthetic machinery [11].

The use of bacterial inoculation on plants for stress alleviation and plant growth promotion has been regarded as an economically feasible and sustainable approach for salt stress amelioration [12]. Plant growth promoting bacteria (PGPB) can enhance plant growth and alleviate salt stress by increasing total plant biomass [13] by enhancing nutrient uptake [14], upregulating ROS scavenging enzymes [15], reducing stress ethylene levels by 1-aminocyclopropane-1-carboxylate (ACC) deaminase activity [16], fixing atmospheric nitrogen [17] and colonizing root architecture [18]. Brevibacterium linens RS16, which was isolated from the coastal regions of South Korea [19], is known to be a potential PGPB [14]. It has been shown that [14], the inoculation of $B$. linens RS16 reduced stress ethylene levels in red pepper seedlings under salt stress conditions. Similarly, the inoculation of B. linens RS16 on rice cultivars regulated the stress volatile compound levels under salt stress conditions [20].

Rice (Oryza sativa L.) is regarded as one of the major food crops across the world and is cultivated from warm temperate to tropical regions. Rice plants are generally susceptible to salt stress, which leads to reduction in growth, grain yield and development [21]. In this study, we hypothesized that salt stress would affect the growth and development of the salt-sensitive rice genotype (IR29) more adversely compared to the moderately salt-tolerant cultivar (FL478) due to inherent genotypic differences. The better tolerance of the moderately salttolerant cultivar (FL478) will be due to the higher accumulation of proline and glycine betaine compared to the salt-sensitive cultivar (IR29). However, the inoculation of Brevibacterium linens RS16 will alleviate salt stress effects and enhance plant growth of both the genotype, but the increase in growth and development of the saltsensitive genotype (IR29) will be more profound compared to the moderately salt-tolerant genotype. The increase in growth of plants will be due to the higher accumulation of proline and glycine betaine after bacterial inoculation. Specifically, this study was conducted to: (i) evaluate the variation in growth parameters of the salt-sensitive genotype (IR29) and the moderately salttolerant genotype (FL478) under salt stress conditions, (ii) assess the time dependent changes in proline and glycine betaine accumulation and enhancement of growth parameters in both the genotypes after inoculation of $B$. linens RS16 under salt stress, and (iii) investigate the correlation between plant biomass and total accumulation of proline and glycine betaine under salt stress and $B$. linens RS16 inoculation between the salt-sensitive (IR29) and the moderately salt-tolerant (FL478) genotypes.

\section{Materials and methods}

\section{Plant materials and growth conditions}

Two rice cultivars, namely; IR29, which is salt-sensitive and FL478, moderately salt-tolerant were used. The rice cultivars were developed at the International Rice Research Institute (IRRI, Philippines), and seeds are maintained at the Rural Development Administration (RDA), South Korea. The seeds were surface-sterilized with $1 \%(\mathrm{v} / \mathrm{v})$ sodium hypochlorite for $20 \mathrm{~min}$ followed by washing with de-ionized water as previously described [22]. Prior to rehydration for $1 \mathrm{~h}$ at room temperature in $100 \mathrm{~mL}$ autoclaved de-ionized water, the seeds were rinsed 5-8 times with sterile distilled water [22]. To check for the efficiency of seed sterilization, $100 \mu \mathrm{L}$ of the final rinse was plated onto nutrient agar plates. The surface sterilized seeds were bacterized for $4 \mathrm{~h}$ with $B$. linens RS16, which were harvested at late $\log$ phase using the method as previously described [23]. Briefly, B. linens RS16 was grown in Nutrient Broth (NB) media (Merck KGaA, 64271 Darmstadt Germany) at $30{ }^{\circ} \mathrm{C}$ for $24 \mathrm{~h}$ at $150 \mathrm{rpm}$. The grown inoculum was harvested at $8000 \mathrm{rpm}$ for $10 \mathrm{~min}$ at $4{ }^{\circ} \mathrm{C}$, and the cell pellets were washed 3 times and re-suspended in $0.03 \mathrm{M}$ $\mathrm{MgSO}_{4}$ to obtain an optical density of 0.8 at $600 \mathrm{~nm}$ (cell count $\sim 1.0 \times 10^{8} \mathrm{CFU} \mathrm{mL} \mathrm{mL}^{-1}$ ). The un-inoculated control seeds were soaked in sterile $0.03 \mathrm{M} \mathrm{MgSO}_{4}$. An equal amount of surface sterilized seeds (max. 30 seeds per petri dish) was placed on Petri dishes containing two layers of filter papers that were moistened with de-ionized water. The seeds placed in Petri dishes were then incubated at $28{ }^{\circ} \mathrm{C}$ with $24 \mathrm{~h}$ dark condition for 3-4 days to facilitate germination. Following germination, seedlings were transferred to plastic pots $(9 \mathrm{~cm} \times 9 \mathrm{~cm} \times 9 \mathrm{~cm})$ containing $175 \mathrm{~g}$ of nursery soil (Doobaena: coco peat $23 \%$, peat moss $9 \%$, vermiculite $30 \%$, sandy loam $15 \%$, 
diatomite $17.5 \%$, bottom ash $5 \%$, fertilizer $0.48 \%$, wetting agent $0.02 \%$ ). The plants were watered below water holding capacity. The bacterized and non-bacterized seedlings were transferred to the greenhouse, and grown in a controlled environment at $25-30{ }^{\circ} \mathrm{C}$ with $60-70 \%$ relative humidity and a 15-9 h day/night period [24].

This study used six treatments $(0 \mathrm{mM} \mathrm{NaCl}, 0 \mathrm{mM}$ $\mathrm{NaCl}+\mathrm{RS} 16, \quad 50 \mathrm{mM} \mathrm{NaCl}, \quad 50 \mathrm{mM} \mathrm{NaCl}+\mathrm{RS} 16$, $150 \mathrm{mM} \mathrm{NaCl}, 150 \mathrm{mM} \mathrm{NaCl}+\mathrm{RS} 16)$, two time points (3 and 10 days after salt stress imposition), four individual plants for each replicate (for each time point, treatment and cultivar), three replications and two different rice cultivars. A total of 288 individual plants were used in this study.

\section{Bacterial inoculation}

Bacterial inoculations were carried out at 7 and 14 days after transplanting the rice seedlings. $B$ linens RS16 was allowed to grow in $\mathrm{NB}$ media until $\mathrm{OD}_{600}$ reached 0.8 . The grown culture was centrifuged at $8000 \mathrm{rpm}$ for $10 \mathrm{~min}$ at $4{ }^{\circ} \mathrm{C}$, and cell pellets were re-suspended in $0.03 \mathrm{M}$ $\mathrm{MgSO}_{4}$. The absorbance was adjusted to an optical density of 0.8 at $600 \mathrm{~nm}$ (cell count $\sim 1.0 \times 10^{8} \mathrm{CFU} \mathrm{mL}^{-1}$ ). Ten $\mathrm{mL}(10 \mathrm{~mL})$ bacterial suspension was applied near the root zone [25]. The un-inoculated control plants were treated with only $0.03 \mathrm{M} \mathrm{MgSO}_{4}$ at the time of inoculation.

\section{Salt stress treatment}

Salt stress was applied at two different levels, $50 \mathrm{mM}$ $\mathrm{NaCl}$ and $150 \mathrm{mM} \mathrm{NaCl}$. Briefly, 21 day old rice seedlings were treated with $10 \mathrm{~mL}$ of $50 \mathrm{mM} \mathrm{NaCl}$ and $150 \mathrm{mM}$ $\mathrm{NaCl}$ near the root zone and the salt treatment was applied at once [26]. Plants were harvested after 3 and 10 days of salt stress imposition. The un-inoculated and bacteria inoculated plants were watered below water holding capacity throughout the treatment period.

\section{Determination of plant growth parameters}

Plant growth parameters were analyzed in terms of shoot length, root length, total length, total fresh weight and plant dry weight at 3 and 10 days after salt treatment. Sample plants were harvested at 3 and 10 days after salt imposition. Roots were washed carefully in running water to remove soil and dried them using blotting paper and subsequently the shoot and root lengths were measured. The plant dry weight was determined by drying the shoot and the root of individual plants in hot air oven at $70{ }^{\circ} \mathrm{C}$ for $72 \mathrm{~h}$ [27].

\section{Determination of proline concentration}

The proline concentration in shoots and roots of both rice cultivars was measured as previously described [28]. Four plants were taken and made into a composite sample for each treatment to measure the proline concentration. Plant tissues $(0.5 \mathrm{~g})$ were taken from the composite sample and homogenized in $10 \mathrm{~mL}$ of $3 \%$ sulfosalycylic acid using mortar and pestle. The samples were then taken in $40 \mathrm{~mL}$ centrifuge tubes and centrifuged at $9000 \mathrm{rpm}$ for $10 \mathrm{~min}$ at $4{ }^{\circ} \mathrm{C}$. For colorimetric determinations, $2 \mathrm{~mL}$ of supernatant was taken and mixed with ninhydrin and glacial acetic acid with a ratio of 1:1:1. The mixtures were incubated at $100{ }^{\circ} \mathrm{C}$ for $1 \mathrm{~h}$ followed by cooling in an ice bath. The chromophore was extracted using $4 \mathrm{~mL}$ of toluene and its absorbance at $520 \mathrm{~nm}$ was determined by a spectrophotometer (NEO-D3117 UV-VIS). The concentration of free proline in the solution was determined by preparing a range of proline standards.

\section{Determination of glycine betaine concentration}

The glycine betaine (GB) concentration in shoots and roots of both cultivars was measured according to the protocol as previously described [29]. Briefly, dried and finely ground plant materials $(0.5 \mathrm{~g})$ was mechanically shaken with $20 \mathrm{~mL}$ of de-ionized water for $24 \mathrm{~h}$ at $25^{\circ} \mathrm{C}$. The samples were then filtered, and the filtrates were diluted (1:1) with $2 \mathrm{~N} \mathrm{H}_{2} \mathrm{SO}_{4}$. Aliquots $(0.5 \mathrm{~mL})$ of the filtrate were taken into centrifuge tubes, and cooled in ice water for $1 \mathrm{~h}$. Cold $\mathrm{KI}-\mathrm{I}_{2}(0.2 \mathrm{~mL})$ was added and then the mixture were gently stirred. The tubes were stored at $4{ }^{\circ} \mathrm{C}$ for $16 \mathrm{~h}$ and then centrifuged at 10,000 rpm for $15 \mathrm{~min}$ at $0{ }^{\circ} \mathrm{C}$. The supernatant was carefully aspirated with a fine tipped glass tube. The per-iodide crystals were dissolved in $9.0 \mathrm{~mL}$ of 1,2-dichloroethane and mixed vigorously. After $2 \mathrm{~h}$, the absorbance was measured at $365 \mathrm{~nm}$ using a spectrophotometer (NEO-D3117 UV-VIS). Reference standards of glycine betaine $(50-200 \mu \mathrm{g} / \mathrm{mL})$ were prepared in $1 \mathrm{~N} \mathrm{H}_{2} \mathrm{SO}_{4}$.

\section{Data analysis}

Generalized linear model (GLM) based on maximum likelihood model fitting was used to analyze the statistical impact of four-way ANONA and three-way ANOVA for main and interactive effects of cultivars, salt, bacteria, and time on growth parameters, proline and glycine betaine concentrations. The significant differences between the means and correlation coefficients were determined by Tukey's test at $\mathrm{p}<0.05,0.01$ and 0.001 using SAS package, Version 9.4.

\section{Results}

ANOVA results for the effects of salt stress and B. linens RS16 inoculation on growth parameters of salt-sensitive and salt-tolerant rice cultivars

The results of the three-way factorial ANOVAs for the salt-sensitive cultivar (IR29) and the moderately 
salt-tolerant cultivar (FL478) displaying the effects of different main factors: time (days after salt stress imposition), B. linens RS16 inoculation and salt stress, as well as the interactions of these factors on the growth parameters and the accumulation of proline and glycine betaine are presented in Tables 1 and 2. For IR29, the effects of the main factors: time, bacterial inoculation and salt stress treatments, were all significant on all the growth parameters considered in the study. Except for salt stress effect, other factors had a significant effect on total proline accumulation in IR29 while all the main factors had a significant effect on total glycine betaine accumulation. The interactive effect of time and bacteria (Time $\times$ Bacteria) had a significant effect on the shoot length, total DW, total proline and glycine betaine accumulation. The interactive effect of time and salt (Time $\times$ Salt) on the shoot length and total proline accumulation were significant. The interactive effect of bacteria and salt (Bacteria $\times$ Salt) had only a significant effect on total glycine betaine accumulation in IR29 (Table 1). In the case of the moderately salt-tolerant cultivar, FL478, the effects of the main factors were significant except for the effect of time on the root length and the effects of bacterial inoculation on root length and shoot length, Bacteria and salt had no significant effect on total proline accumulation and salt had no significant effect on total glycine betaine accumulation. Interaction effects between time and bacteria were significant for total dry weight and time and salt for the shoot length, total length and total glycine betaine accumulation in FL478 (Table 2).

\section{Effects of salt stress and inoculation of B. linens RS16 on growth parameters in rice cultivars}

Plant growth is generally constrained under increasing levels of soil salinity. Rice cultivars with differing tolerance to salinity stress may also behave differently under salt stress conditions. The inoculation effects of $B$. linens RS16 on the salt-sensitive cultivar (IR29) and the moderately salt-tolerant cultivar (FL478) grown under $50 \mathrm{mM}$ and $150 \mathrm{mM}$ of salt stress were studied in terms of its

Table 1 Results of the three-way ANOVA using the general linear model $(\mathrm{glm})$ for comparing three factors of experiments in the saltsensitive cultivar (IR29)

\begin{tabular}{|c|c|c|c|c|c|c|c|c|}
\hline Cultivars & Source of variation & DF & $\begin{array}{l}\text { Root } \\
\text { length } \\
\text { (cm) }\end{array}$ & $\begin{array}{l}\text { Shoot } \\
\text { length } \\
\text { (cm) }\end{array}$ & $\begin{array}{l}\text { Total } \\
\text { length } \\
\text { (cm) }\end{array}$ & Total DW (mg) & $\begin{array}{l}\text { Total proline } \\
\text { accumulation }(\mu \mathrm{g} / \\
\text { plant) }\end{array}$ & $\begin{array}{l}\text { Total GB } \\
\text { accumulation } \\
\text { ( } \mu \mathrm{g} / \text { plant) }\end{array}$ \\
\hline \multirow[t]{7}{*}{ IR29 } & Time & 1 & * & $* * *$ & $* * *$ & $* * *$ & $* * *$ & $* * *$ \\
\hline & Bacteria & 1 & $* *$ & $* * *$ & $* * *$ & $* * *$ & $* * *$ & $* * *$ \\
\hline & Salt & 2 & $* * *$ & $* * *$ & $* * *$ & $* * *$ & NS & $* * *$ \\
\hline & Time $\times$ bacteria & 1 & NS & $* *$ & NS & $* * *$ & $* * *$ & $* *$ \\
\hline & Time $\times$ salt & 2 & NS & $* *$ & NS & NS & $* *$ & NS \\
\hline & Bacteria $\times$ salt & 2 & NS & NS & NS & NS & NS & * \\
\hline & Time $\times$ bacteria $\times$ salt & 2 & NS & NS & NS & NS & NS & NS \\
\hline
\end{tabular}

NS Non-significant

*** $p<0.001,{ }^{* *} p<0.01,{ }^{*} p<0.05$

Table 2 Results of the three-way ANOVA using the general linear model ( $\mathrm{glm}$ ) for comparing three factors of experiments in the moderately salt-tolerant cultivar (FL478)

\begin{tabular}{|c|c|c|c|c|c|c|c|c|}
\hline Cultivars & Source of variation & DF & $\begin{array}{l}\text { Root } \\
\text { length } \\
(\mathrm{cm})\end{array}$ & $\begin{array}{l}\text { Shoot } \\
\text { length } \\
(\mathrm{cm})\end{array}$ & $\begin{array}{l}\text { Total } \\
\text { length } \\
(\mathrm{cm})\end{array}$ & Total DW (mg) & $\begin{array}{l}\text { Total proline } \\
\text { accumulation }(\mu \mathrm{g} / \\
\text { plant) }\end{array}$ & $\begin{array}{l}\text { Total GB } \\
\text { accumulation } \\
\text { ( } \mu \text { g/plant) }\end{array}$ \\
\hline \multirow[t]{7}{*}{$\mathrm{FL478}$} & Time & 1 & NS & $* * *$ & $* * *$ & $* * *$ & $* * *$ & $* * *$ \\
\hline & Bacteria & 1 & NS & NS & $* *$ & $* *$ & NS & NS \\
\hline & Salt & 2 & $* *$ & $* * *$ & $* * *$ & $* * *$ & NS & $* * *$ \\
\hline & Time $\times$ bacteria & 1 & NS & NS & NS & * & NS & NS \\
\hline & Time $\times$ salt & 2 & NS & $*$ & $* *$ & NS & NS & $* *$ \\
\hline & Bacteria $\times$ salt & 2 & NS & NS & NS & NS & NS & NS \\
\hline & Time $\times$ bacteria $\times$ salt & 2 & NS & NS & NS & NS & NS & NS \\
\hline
\end{tabular}

NS Non-significant

${ }^{*}{ }^{* *} p<0.001,{ }^{* *} p<0.01,{ }^{*} p<0.05$ 
ability to enhance various plant growth parameters. The salt mitigating efficacy of the inoculant was assessed by recording the percent increase in plant growth parameters at 3 and 10 days after imposing salt stress.

The root length of the salt-sensitive cultivar (IR29) had decreased under $50 \mathrm{mM}$ and $150 \mathrm{mM}$ of salt stress compared to $0 \mathrm{mM}$ at 3 and 10 days after salt stress imposition. The inoculation of B. linens RS16 had significantly increased the root length of IR 29 by $28 \%$ under $50 \mathrm{mM}$ salt 3 days after stress imposition. However, the inoculation of B. linens RS16 on plants exposed to higher salt stress of $150 \mathrm{mM}$ did not have any significant effect on the growth parameters. Similarly, the inoculation of $B$. linens RS16 had no significant effect on the root length of IR29 exposed to salt stress for 10 days (Table 3). For the moderately salt-tolerant rice cultivar, FL478, there was no significant differences in the root length under salt stress conditions and B. linens RS16 inoculation (Table 4).

The shoot length of IR29 significantly decreased after imposing $50 \mathrm{mM}$ and $150 \mathrm{mM}$ of salt stress at 3 and 10 days compared to control (Additional file 1: Table S1). Inoculation of $B$. linens RS16 increased the shoot length significantly in both non-stressed and salt stressed IR29 plants. B. linens RS16 inoculation of 3 days salt stressed plants, showed significant increase in shoot length by $13 \%$ at $50 \mathrm{mM}$ salt stress concentration. Similarly,

Table 3 Effects of inoculation by B. linens RS16 on growth parameters of the salt-sensitive cultivar (IR29)

\begin{tabular}{|c|c|c|c|c|c|c|c|}
\hline Variety & $\begin{array}{l}\text { Day after salt } \\
\text { treatment }\end{array}$ & Inoculation & $\begin{array}{l}\text { Salt } \\
\text { concentration } \\
(\mathrm{mM})\end{array}$ & Root length $(\mathrm{cm})$ & Shoot length $(\mathrm{cm})$ & Total length (cm) & Plant dry weight (mg) \\
\hline \multirow[t]{12}{*}{ IR29 } & \multirow[t]{6}{*}{3 day } & Mock & 0 & $13.62 \pm 0.86^{\mathrm{a}}$ & $28.16 \pm 0.71^{a}$ & $41.78 \pm 1.02^{b}$ & $85.61 \pm 2.81^{b}$ \\
\hline & & $\mathrm{RS} 16$ & 0 & $17.55 \pm 1.35^{\mathrm{a}}$ & $29.17 \pm 0.09^{a}$ & $46.72 \pm 1.28^{\mathrm{a}}$ & $112.37 \pm 7.02^{a}$ \\
\hline & & Mock & 50 & $13.03 \pm 1.15^{b}$ & $24.38 \pm 0.19^{b}$ & $37.41 \pm 1.14^{b}$ & $76.14 \pm 6.59^{a}$ \\
\hline & & RS16 & 50 & $16.68 \pm 0.27^{a}$ & $27.50 \pm 0.89^{a}$ & $44.18 \pm 0.82^{\mathrm{a}}$ & $90.58 \pm 6.79^{a}$ \\
\hline & & Mock & 150 & $11.23 \pm 0.19^{\mathrm{a}}$ & $16.58 \pm 1.42^{\mathrm{a}}$ & $27.82 \pm 1.41^{\mathrm{a}}$ & $48.21 \pm 4.93^{\mathrm{a}}$ \\
\hline & & $\mathrm{RS} 16$ & 150 & $12.40 \pm 0.78^{\mathrm{a}}$ & $18.86 \pm 0.33^{a}$ & $31.26 \pm 0.83^{\mathrm{a}}$ & $59.98 \pm 4.13^{\mathrm{a}}$ \\
\hline & \multirow[t]{6}{*}{10 day } & Mock & 0 & $16.73 \pm 1.10^{\mathrm{a}}$ & $30.85 \pm 0.67^{b}$ & $47.58 \pm 1.77^{\mathrm{a}}$ & $108.24 \pm 0.73^{b}$ \\
\hline & & $\mathrm{RS} 16$ & 0 & $19.52 \pm 2.27^{\mathrm{a}}$ & $35.80 \pm 0.88^{a}$ & $55.32 \pm 2.82^{\mathrm{a}}$ & $144.28 \pm 0.14^{a}$ \\
\hline & & Mock & 50 & $14.61 \pm 1.75^{\mathrm{a}}$ & $25.35 \pm 0.37^{b}$ & $39.96 \pm 1.94^{b}$ & $80.27 \pm 1.06^{b}$ \\
\hline & & RS16 & 50 & $16.94 \pm 1.08^{\mathrm{a}}$ & $31.70 \pm 0.97^{a}$ & $48.64 \pm 0.14^{\mathrm{a}}$ & $134.34 \pm 0.68^{a}$ \\
\hline & & Mock & 150 & $12.67 \pm 1.00^{\mathrm{a}}$ & $21.45 \pm 0.14^{b}$ & $34.12 \pm 0.91^{b}$ & $55.08 \pm 3.09^{b}$ \\
\hline & & $\mathrm{RS} 16$ & 150 & $12.78 \pm 0.30^{\mathrm{a}}$ & $27.08 \pm 1.19^{\mathrm{a}}$ & $39.86 \pm 1.13^{a}$ & $92.40 \pm 4.11^{a}$ \\
\hline
\end{tabular}

For each number in a column, values (mean $\pm \mathrm{SE}$, number of replications $=3$ ) represented by the same lower-case letters are not significantly different at $\mathrm{p}<0.05$

Table 4 Effects of inoculation by B. linens RS16 on growth parameters of the moderately salt-tolerant cultivar (FI478)

\begin{tabular}{|c|c|c|c|c|c|c|c|}
\hline Variety & $\begin{array}{l}\text { Day after salt } \\
\text { treatment }\end{array}$ & Inoculation & $\begin{array}{l}\text { Salt } \\
\text { concentration } \\
(\mathrm{mM})\end{array}$ & Root length $(\mathrm{cm})$ & Shoot length $(\mathrm{cm})$ & Total length $(\mathrm{cm})$ & Total dry weight (mg) \\
\hline \multirow[t]{12}{*}{ FL478 } & \multirow[t]{6}{*}{3 day } & Mock & 0 & $14.77 \pm 0.83^{\mathrm{a}}$ & $30.48 \pm 0.29^{a}$ & $45.24 \pm 1.12^{\mathrm{a}}$ & $125.06 \pm 1.45^{a}$ \\
\hline & & RS16 & 0 & $15.56 \pm 1.92^{\mathrm{a}}$ & $31.29 \pm 0.29^{\mathrm{a}}$ & $46.85 \pm 2.09^{\mathrm{a}}$ & $132.70 \pm 7.05^{\mathrm{a}}$ \\
\hline & & Mock & 50 & $16.53 \pm 0.27^{\mathrm{a}}$ & $28.98 \pm 0.84^{\mathrm{a}}$ & $45.51 \pm 1.04^{\mathrm{a}}$ & $107.03 \pm 6.23^{\mathrm{a}}$ \\
\hline & & RS16 & 50 & $17.22 \pm 1.25^{\mathrm{a}}$ & $29.43 \pm 0.36^{\mathrm{a}}$ & $46.65 \pm 1.35^{\mathrm{a}}$ & $115.53 \pm 3.39^{\mathrm{a}}$ \\
\hline & & Mock & 150 & $12.59 \pm 1.22^{\mathrm{a}}$ & $23.38 \pm 1.63^{\mathrm{a}}$ & $35.97 \pm 0.42^{b}$ & $67.78 \pm 8.05^{a}$ \\
\hline & & RS16 & 150 & $14.24 \pm 0.58^{\mathrm{a}}$ & $24.85 \pm 1.03^{\mathrm{a}}$ & $39.09 \pm 0.49^{a}$ & $73.88 \pm 2.49^{\mathrm{a}}$ \\
\hline & \multirow[t]{6}{*}{10 day } & Mock & 0 & $16.31 \pm 0.35^{\mathrm{a}}$ & $38.37 \pm 1.01^{\mathrm{a}}$ & $54.68 \pm 0.74^{\mathrm{a}}$ & $160.06 \pm 5.83^{b}$ \\
\hline & & RS16 & 0 & $17.54 \pm 0.99^{\mathrm{a}}$ & $38.83 \pm 0.84^{\mathrm{a}}$ & $56.38 \pm 0.28^{\mathrm{a}}$ & $178.86 \pm 0.82^{\mathrm{a}}$ \\
\hline & & Mock & 50 & $16.10 \pm 0.95^{\mathrm{a}}$ & $36.84 \pm 1.27^{\mathrm{a}}$ & $52.94 \pm 1.78^{\mathrm{a}}$ & $145.05 \pm 9.17^{\mathrm{a}}$ \\
\hline & & RS16 & 50 & $16.18 \pm 0.15^{a}$ & $38.43 \pm 0.55^{\mathrm{a}}$ & $54.62 \pm 0.69^{a}$ & $166.60 \pm 5.66^{a}$ \\
\hline & & Mock & 150 & $15.14 \pm 0.78^{\mathrm{a}}$ & $34.58 \pm 1.05^{\mathrm{a}}$ & $49.73 \pm 0.43^{\mathrm{a}}$ & $101.11 \pm 1.48^{b}$ \\
\hline & & RS16 & 150 & $15.23 \pm 0.53^{\mathrm{a}}$ & $36.38 \pm 1.03^{\mathrm{a}}$ & $51.60 \pm 1.45^{\mathrm{a}}$ & $121.12 \pm 3.02^{\mathrm{a}}$ \\
\hline
\end{tabular}


bacterial inoculation resulted in significant increases of $25 \%$ and $26 \%$ in shoot length of plants stressed at $50 \mathrm{mM}$ and $150 \mathrm{mM}$ for 10 days, respectively (Table 3 ). However, the inoculation of B. linens RS16 on FL478 had no significant effect on shoot length at $50 \mathrm{mM}$ and $150 \mathrm{mM}$ salt stress (Table 4).

The total length of IR29) had significantly decreased under $50 \mathrm{mM}$ and $150 \mathrm{mM}$ salt stress at 10 days compared to $0 \mathrm{mM}$ (Additional file 1: Table S2). However, after inoculation of $B$. linens RS16, the total length significantly increased under $50 \mathrm{mM}$ salt stress after 3 $(18.1 \%)$ and $10(22 \%)$ days while a significant increase was observed at $150 \mathrm{mM}$ salt stress only at 10 days (17\%) (Table 3). For the moderately salt-tolerant rice cultivar, FL478, a significant increase in total length (9\%) was only observed under $150 \mathrm{mM}$ salt stress at 3 days (Table 4).

Salt stress negatively impacted the total fresh weight of the rice plants. This was more pronounced in IR29 at the higher salt stress level. Inoculation of B. linens RS16, significantly increased the total fresh weight of IR29 at 10 days after salt imposition under $50 \mathrm{mM}(49.6 \%)$ and $150 \mathrm{mM}(52.8 \%)$ salt stress. For the moderately salt-tolerant rice cultivar, FL478, significant increase (33.6\%) in total fresh weight was only observed under $150 \mathrm{mM}$ salt stress at 10 days after salt imposition (Fig. 1).

\section{Percent increase in total dry weight by $B$. linens RS16 inoculation in salt-sensitive cultivar (IR29)} and the moderately salt-tolerant cultivar (FL478)

The total plant biomass is an important feature to assess the effect of salinity as well as the efficient role of an inoculant to alleviate salt stress. The total plant biomass was measured in terms of total plant dry weight and it was observed that the salt stressed plants generally have lower dry matter compared to the nonstressed plants. However, the inoculation of $B$. linens RS16 has significantly increased the total dry weight of both the salt-sensitive (IR29) and the moderately salttolerant (FL478) cultivars. Salt stress at $150 \mathrm{mM}$ significantly decreased the total dry weight of both rice cultivars after 3 and 10 days after salt imposition (Additional file 1: Table S3). The total dry weight of IR29 and FL478 increased significantly with inoculation with $B$. linens RS16.

The inoculation of $B$. linens RS16 on IR29 enhanced the total plant dry weight for both control and salt stressed plants. Inoculation resulted in significant increase in total dry weight of control plants after 3 and 10 days after salt imposition by $31.59 \%$ and $33.31 \%$, respectively. Furthermore, inoculation of $B$. linens RS16 had significantly increased the total dry weight of IR29 under $50 \mathrm{mM}$ of salt stress after 3 days (19.30\%) and 10 days (67.43\%) after salt stress imposition. Similarly, inoculation resulted in $25.40 \%$ and $69.54 \%$ increase in total dry weight at 3 and 10 days after salt stress imposition, respectively, under $150 \mathrm{mM}$ salt stress (Fig. 2; Table 3).

The inoculation of $B$. linens RS16 also increased the dry weight of the moderately salt-tolerant cultivar (FL478) by $8.38 \%$ and $11.68 \%$ under $50 \mathrm{mM}$ and $150 \mathrm{mM}$ salt stress at 3 days after salt imposition, respectively. Whereas, the increase in total dry weight resulted in $15.75 \%$ and $19.78 \%$ increase in total dry weight under $50 \mathrm{mM}$ and $150 \mathrm{mM}$ salt stress, respectively, at 10 days after salt stress imposition compared to the un-inoculated plants. There was no significant difference in the increase of total dry weight when compared to plants which were

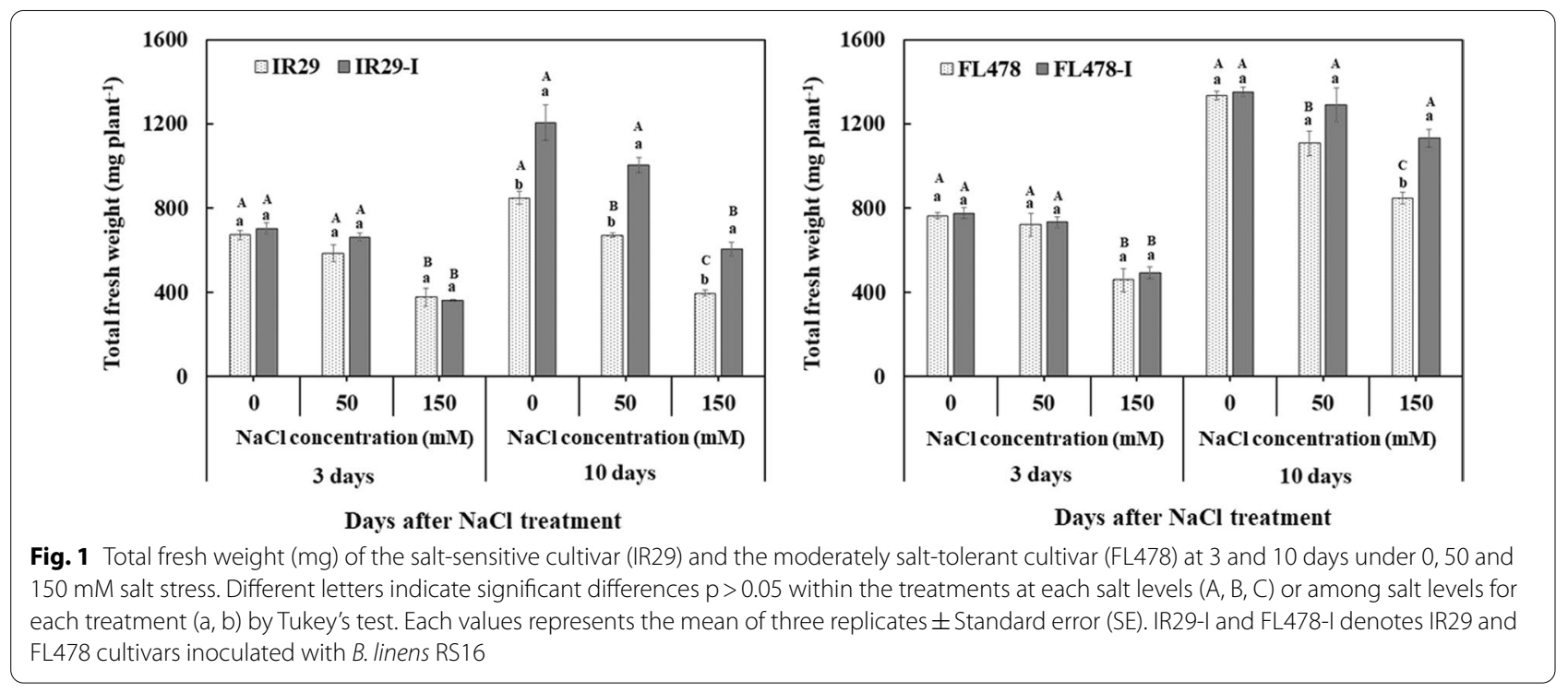




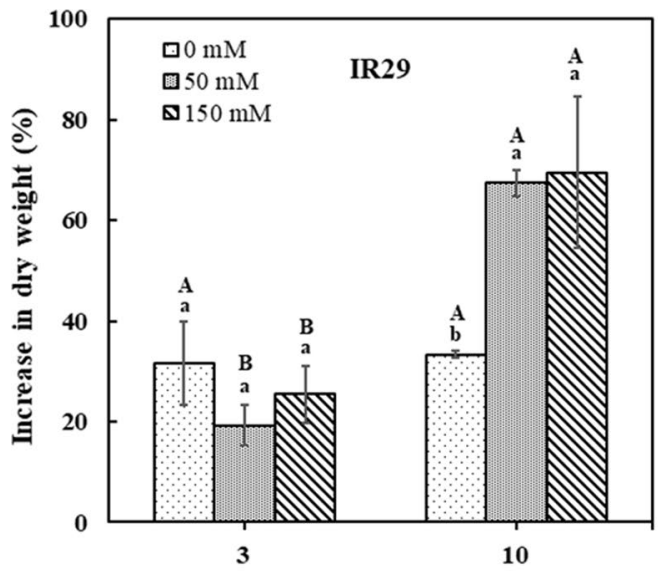

Days after $\mathrm{NaCl}$ treatment

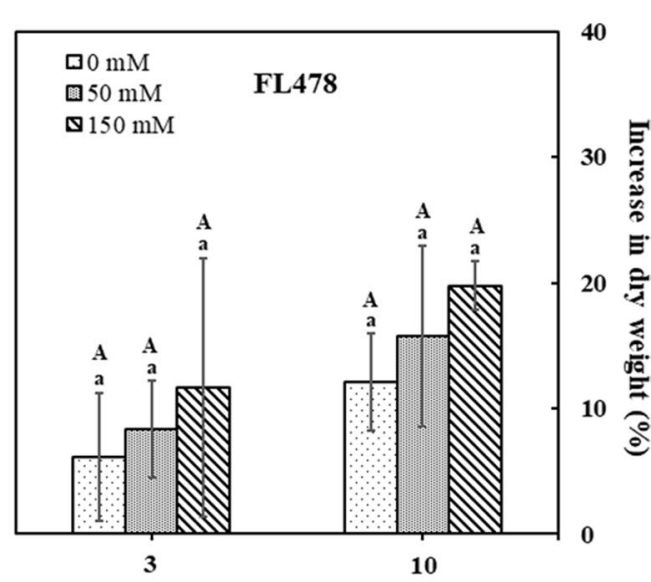

Days after NaCl treatment

Fig. 2 Percent increase in total dry weight by inoculation of B. linens RS16 in the salt-sensitive cultivar (IR29) and the moderately salt-tolerant cultivar (FL478) at 3 and 10 days under salt stress. Different letters indicate significant differences at $p<0.05$ among different salt concentration for each day $(a, b)$ and among each salt level for different days (A, B)

inoculated with $B$. linens RS16 but not treated with salt stress (Fig. 2; Table 4).

\section{Proline accumulation in rice cultivars}

The proline accumulation in the whole plant was significantly higher in B. linens RS16 inoculated salt-sensitive cultivar (IR29) after imposing $50 \mathrm{mM}$ and $150 \mathrm{mM}$ salt stress for 10 days compared to non-inoculated plants. The moderately salt-tolerant cultivar (FL478) had no significant proline accumulation in the whole plant at 10 days after imposing salt stress. However, the inoculation of $B$. linens RS16 on IR29 resulted in no significant effect in the total proline accumulation under $50 \mathrm{mM}$ (3.7\% decrease) and $150 \mathrm{mM}$ (14.1\% increase) of salt stress after 3 days. On the other hand, 10 days under salt stress resulted in a significant increase by $35.7 \%$ and $37.7 \%$ in total proline accumulation in the whole plant after imposing $50 \mathrm{mM}$ and $150 \mathrm{mM}$, respectively (Fig. 3). It was also observed that the moderately salt-tolerant cultivar (FL478) showed higher accumulation of total proline in the whole plant
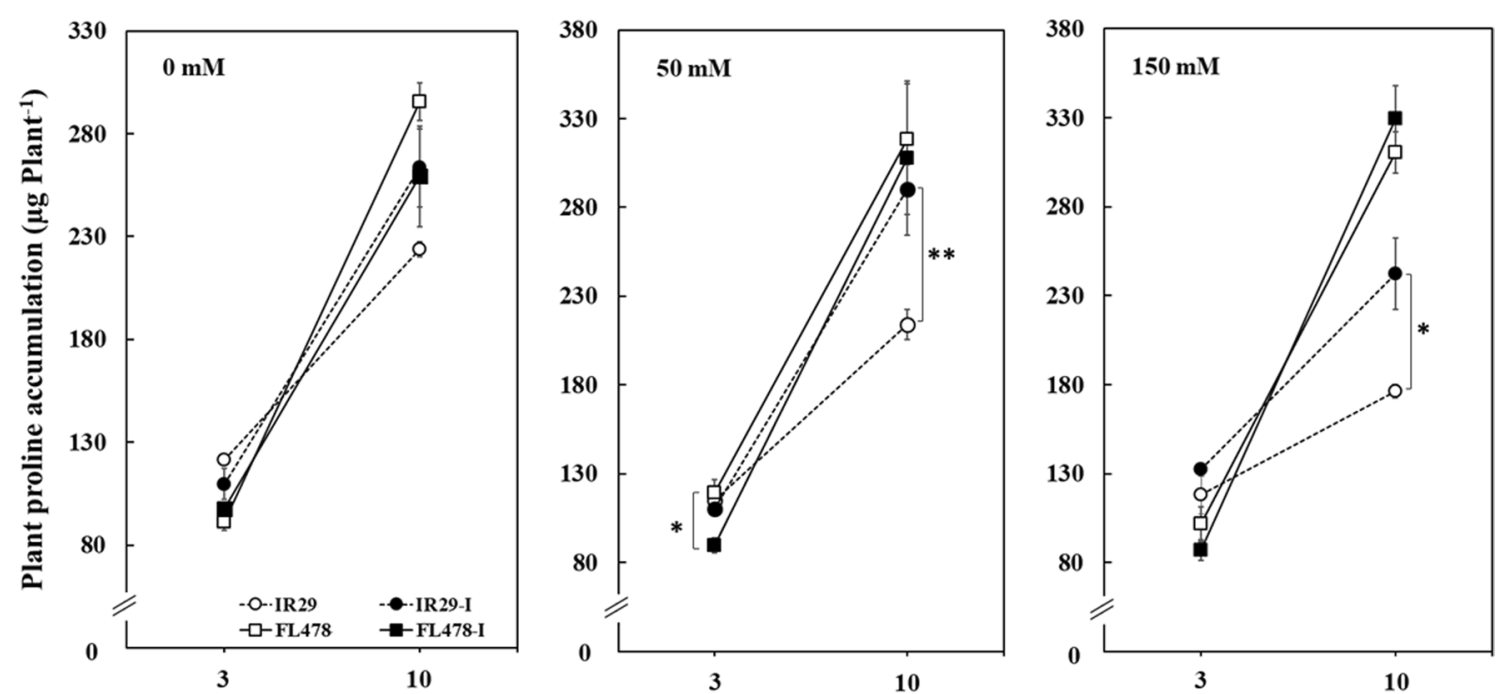

Days after NaCl treatment

Fig. 3 The total proline accumulation ( $\mu \mathrm{g}$ ) of the salt-sensitive cultivar (IR29) and the moderately salt-tolerant cultivar (FL478) at 3 and 10 under 0 , 50 and $150 \mathrm{mM}$ salt stress. ${ }^{*}$ is significant at $\mathrm{p}<0.01{ }^{*}$ is significant at $\mathrm{p}<0.05$. IR29-I and FL478-I denotes IR29 and FL478 cultivars inoculated with B. linens RS16 
after imposing salt stress for 10 days compared to the salt-sensitive cultivar (IR29). However, the inoculation of B. linens RS16 on the moderately salt-tolerant cultivar (FL478) had significantly decreased (24.6\%) total proline under $50 \mathrm{mM}$ salt stress at 3 days and a non-significant decrease (13.4\%) under $150 \mathrm{mM}$ salt stress. There was no significant change on total proline accumulation in the moderately salt-tolerant cultivar (FL478) with the inoculation of $B$. linens RS16 after imposing salt stress at 10 days (Fig. 3).

\section{The correlation between total dry weight and total proline accumulation of both cultivars under salt stress conditions}

Pearson's correlation coefficients were analyzed between the total dry weight and the total proline accumulation in salt treated and untreated IR29 and FL478 rice cultivars. The correlation between the total dry weight and the total proline accumulation of both the salt-sensitive cultivar (IR29) and moderately salt-tolerant cultivar (FL478) irrespective of plant variety was observed to be positively correlated $\left(R^{2}=0.3164\right)$ with a significant correlation coefficient of 0.56 at $\mathrm{p}<0.001$ (Fig. 4A).

The correlation of total dry weight and the whole plant proline accumulation of salt-sensitive cultivar (IR29) and moderately salt-tolerant cultivar (FL478) were positive. The correlation between the two parameters for both the cultivars were positive with an $R^{2}$ values of 0.3751 and 0.3149 for the salt-sensitive cultivar (IR29) and the moderately salt-tolerant cultivar (FL478), respectively (Additional file 1: Figure S1A and
B). The correlation coefficients were highly significant at 0.61 and 0.56 at $\mathrm{p}<0.001$ and $\mathrm{p}<0.01$ for the saltsensitive and moderately salt-tolerant cultivars, respectively (Additional file 1: Figure S1A and B).

\section{Glycine betaine accumulation in rice cultivars}

The glycine betaine accumulation in the whole plant of both cultivars was significantly greater after imposing $50 \mathrm{mM}$ and $150 \mathrm{mM}$ salt stress at 3 and 10 days compared to non-stressed inoculated and non-inoculated plants (Fig. 5). In addition, the glycine betaine accumulation in the whole plant was significantly higher in B. linens RS16 inoculated IR29after imposing $50 \mathrm{mM}$ and $150 \mathrm{mM}$ salt stress for 10 days compared to noninoculated plants. However, in FL478 there was no significant difference in glycine betaine accumulation was observed after imposing salt stress for 3 and 10 days. On the other hand, after 10 days with the same treatment resulted in a significant increase in the total glycine betaine accumulation in the whole plant after imposing $50 \mathrm{mM}$ (38.54\%) and 150 (39.55\%) $\mathrm{mM}$ of salt stress (Fig. 5). The moderately salt-tolerant cultivar (FL478) showed a higher accumulation of glycine betaine in the whole plant after imposing salt stress at 3 and 10 days compared to the salt-sensitive cultivar (IR29). The inoculation of B. linens RS16 on the moderately salt-tolerant cultivar (FL478) showed no significant effect compared to the non-inoculated plant (Fig. 5).
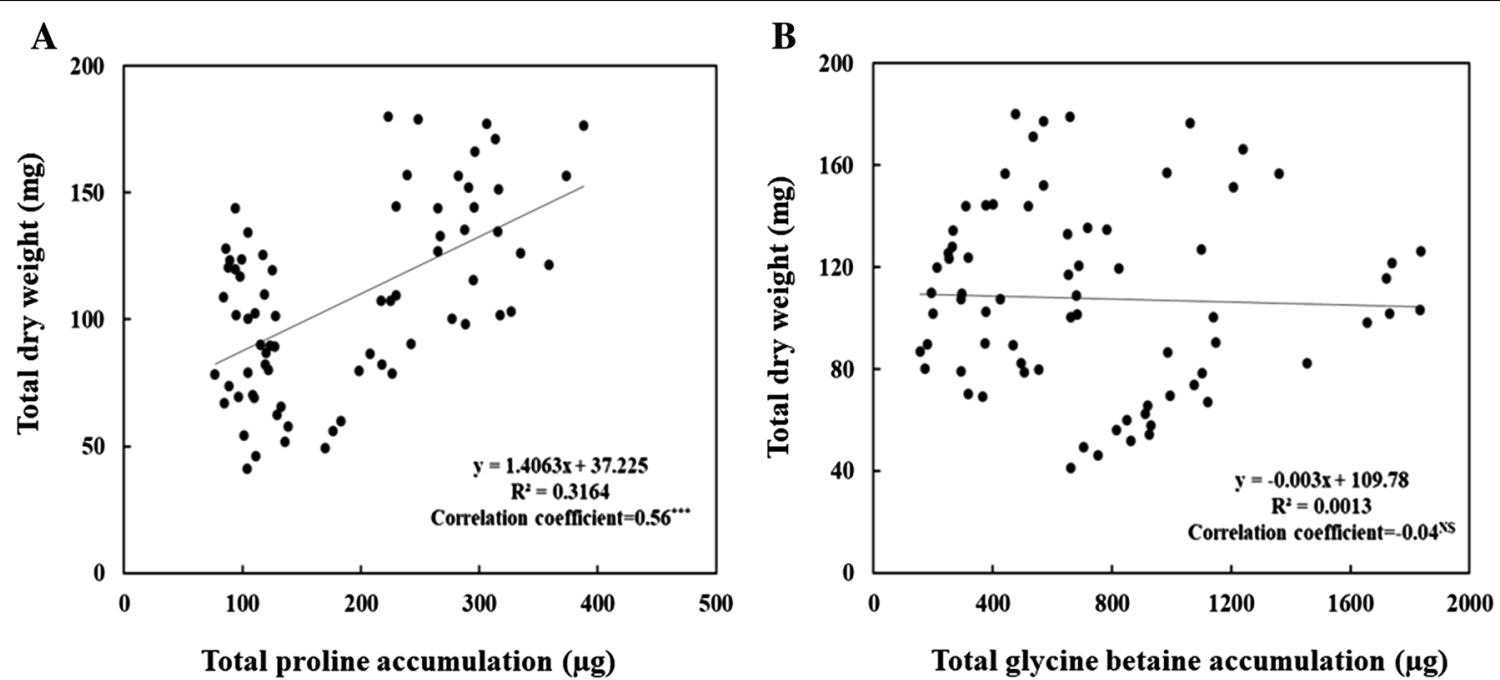

Total glycine betaine accumulation $(\mu \mathrm{g})$

Fig. 4 Correlation between $\mathbf{A}$ total dry weight and total proline accumulation, $\mathbf{B}$ total dry weight and total glycine betaine accumulation of both cultivars under salt stress conditions. A total of 72 observation data (bacteria inoculated and non-inoculated) after salt stress at 3 and 10 days was considered for analysis. ${ }^{* * *}$ signifies a correlation that is significant at $p<0.001$ 

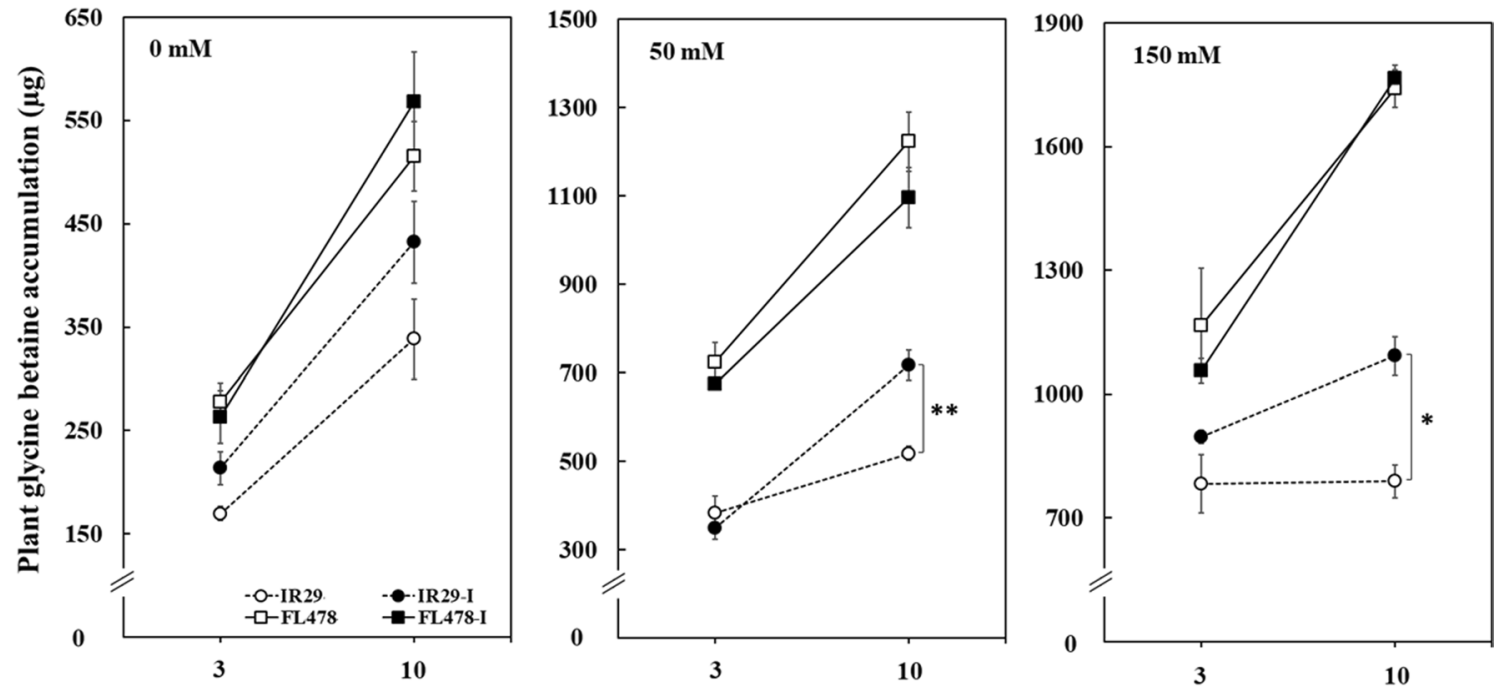

Days after NaCl treatment

Fig. 5 The total glycine betaine accumulation $(\mu \mathrm{g})$ of the salt-sensitive cultivar (IR29) and the moderately salt-tolerant cultivar (FL478) at 3 and 10 days under 0,50 and $150 \mathrm{mM}$ salt stress. ${ }^{* *}$ is significant at $p<0.01$ and * at $p<0.05$. IR29-I and FL478-I denotes IR29 and FL478 cultivars inoculated with B. linens RS16

\section{Correlation between total dry weight and total glycine betaine accumulation of both cultivars under salt stress conditions}

Pearson's correlation coefficients were analyzed between the total dry weight and the total glycine betaine accumulation in the whole plant of salt treated and untreated rice cultivars irrespective of the plant variety (IR29 and FL478). The correlation between the total dry weight and the total glycine betaine accumulation in the whole plant has a very weak correlation with an $R^{2}$ value of 0.0013 and a non-significant correlation coefficient of -0.04 (Fig. 4B).

The correlation between the total dry weight and total glycine betaine accumulation of the salt-sensitive cultivar (IR29) and the moderately salt-tolerant cultivar (FL478) are negative and an $\mathrm{R}^{2}$ values of 0.0938 and 0.0817 , repectively. The correlation coefficients between the total dry weight and total glycine betaine accumulation of the salt-sensitive cultivar (IR29) and the moderately salt-tolerant cultivar (FL478) are also non significant with values of -0.31 and -0.29 since $p>0.05$ (Additional file 1: Figure $\mathrm{S} 1 \mathrm{C}$ and $\mathrm{D})$.

\section{Discussion}

This study was conducted to determine who distinct motivations, viz., how does different rice cultivars accumulate compatible solutes based on their salt tolerance capacity, and how does the bacterial inoculation assist in enhance salt tolerance of rice cultivars through the accumulation of compatible solutes. The overall data suggests that salt tolerant cultivar (FL478) can accumulate higher proline and glycine betaine compared to the salt sensitive cultivar (IR29). Additionally, the inoculation of $B$. linens RS16 had significantly increased proline and glycine betaine accumulation in the salt sensitive rice cultivar (IR29), while no significant effect was observed in salt tolerant cultivar under salt stress conditions.

Rice plants are relatively susceptible to soil salinity, and the degree of sensitivity varies within different kinds of cultivars. Salt stress causes a reduction in soil water potential due to increasing concentration of salts, especially $\mathrm{Na}^{+}$and $\mathrm{Cl}^{-}$. Both ions result in the decrease of root osmotic potential compounded by the accumulation of plant cellular $\mathrm{Na}^{+}$and $\mathrm{Cl}^{-}$ions which determines the physiological difference between the salt-sensitive and the salt-tolerant cultivars on the basis of their rate of $\mathrm{Na}^{+}$ and $\mathrm{Cl}^{-}$ion transport to the leaves [5]. Additionally, salt stress results to physiological and biochemical changes in plant cell by the modulation of non-toxic low molecular weight solutes such as proline and glycine betaine. Compatible solutes, mainly proline and glycine betaine, are synthesized at higher level under salt stress condition to coordinate transport and biochemical processes of plants, thus having roles in both osmoprotection and osmotic adjustment [30]. However, the inoculation of $B$. linens RS16 significantly decreased the extent growth suppression of both the salt-sensitive and the moderately salt-tolerant cultivar and the treated plants showed greater recovery from salt stress than untreated plants, 
which also corroborates to a previous reported study [31].

\section{Salinity negatively affects growth parameters of both salt-sensitive and salt-tolerant rice cultivars and mitigated by inoculation of $B$. linens RS16}

The overall results obtained from the present study indicate that inoculation of $B$. linens RS16 leads to a significant recovery of both cultivars from salt stress as shown in Tables 3 and 4. In general, salinity reduces shoot and root growth by reducing turgor pressure in tissues resulting from lowered water potential in the root. Similar to that, many research had been conducted with comparative analyses between the moderately salt-tolerant cultivar (FL478) and its sensitive counterpart (IR29) which revealed differences in mechanisms of salt tolerance [32]. In agreement to this, our study revealed that the effect of salinity stress had resulted in a substantial reduction in plant growth parameters at 3 and 10 days after imposing $50 \mathrm{mM}$ and $150 \mathrm{mM}$ of salt stress. The reduction in plant growth parameters may also occur due to ion toxicity which can result in disruption of cellular ionic homeostasis and subsequently had a negative impact on physiological growth parameters. Rice plants have time dependent plant response variations with salt stress exposure [33]. In our experiment, the elevated levels of salt stress resulted in a significant decrease of root, shoot and total length, as well as total fresh weight and dry weight in IR29 compared to FL478 (Tables 3 and 4, Fig. 1 and 2). This might be due to the greater disruption of water balance and cellular homeostasis experienced in IR29 compared to FL478 during salt stress conditions [27]. In this study, the reduction in root and shoot length might have been attributed with osmotic imbalance under salt stress condition which results in reductions in cell division and eventually decreasing plant biomass in both cultivars [34]. When both cultivars were exposed to $50 \mathrm{mM}$ of salt stress, FL478 had shown 21\% and 9.25\% higher plant biomass after 3 and 10 days compared to IR29, respectively. Whereas at $150 \mathrm{mM}$ of salt stress condition, FL478 recorded 10.8\% higher plant biomass after 3 days and $16.3 \%$ higher plant biomass after 10 days compared to the salt-sensitive cultivar (IR29). Similar to our results, another study [33] reported around $42 \%$ higher plant biomass in the moderately salt-tolerant cultivar (FL478) than the salt-sensitive cultivar (IR29).

Salt stress exposure causes reduction in water content in the plant tissues, which results in decrease in total fresh weight of the plants [6]. In this study, the salt stress exposure also resulted in decrease of total fresh weight of both the cultivars (Fig. 1). However, the inoculation of $B$. linens RS16 had increased the total fresh weight of both the cultivars, which can be corroborated to a previous study where the fresh weight of Trifolium arvense were enhanced upon inoculation of Pseudomonas azotoformans ASS1 under salt stress conditions [35]. The increase in total fresh weight upon inoculation might be due to the increase in relative water content of the plant tissues [36].

Time-dependent effects of abiotic stresses have been observed previously in response to salt stress [37], drought stress [38], and water stress [39] and have been associated with the generation of oxidative stress in severely stressed leaves. It has been reported that debilitating effects of salt stress on growth parameters may be mitigated and improved by the potential action of plant growth promoting rhizobacteria $B$. linens RS16 [40]. In this study, the inoculation of $B$. linens RS16 significantly recovered the salt stress effects on plant growth characteristics (Tables 3 and 4) of the salt-sensitive cultivar (IR29) compared to the moderately salt-tolerant cultivar (FL478). Several studies have demonstrated the ability of plant growth promotion by bacteria to alleviate salt stress and improve the plant growth [16, 27, 41, 42]. The halotolerant $B$. linens RS16 has been characterized to possess various plant growth promoting characteristics such as nitrogen fixation and phosphorus solubilization [19]. Additionally, it has been shown that the inoculation of B. linens RS16 improved growth of rice and red pepper plant under salt stress conditions $[27,40]$. These results also corroborate to the present study, where the growth parameters such as root, shoot, total length as well as total fresh weight and total dry weight were significantly increased due to bacterial inoculation under salt stress conditions. The enhancement of plant growth parameters by inoculation of $B$. linens RS16 can be attributed to nitrogen fixation and phosphorus solubilization [40]. Furthermore, as B. linens RS16 inoculation enhanced the ion accumulation [14], photosynthesis capacity, net assimilation rate and stomatal conductance [27], it helps rice cultivars to increase dry mass even at $150 \mathrm{mM}$ of salt treatment. On the other hand, IAA activity can enhance the flexibility of plant cell wall and increase the release of saccharides, which helps the microbes to efficiently colonize the plant roots [43]. B. linens RS16 also possess these plant growth promoting characteristics and may be partly responsible for the observed amelioration of salt stress on the salt-sensitive cultivar (IR29) and the moderately salt-tolerant cultivar (FL478) in this experiment.

\section{Inoculation of $B$. linens RS16 improves total dry weight of plants}

The effect of salt stress are variable to different plant species depending upon the level of salt tolerance. The salt-sensitive cultivars have an adverse effect of salt stress compared to the salt-tolerant counterpart [33]. 
Inoculation of plant growth promoting bacteria significantly improve plant growth and total dry weight under different levels of salt stress. Numerous studies have demonstrated the ability of plant growth promoting bacteria to stimulate the growth of a variety of crops such as rice, wheat, red pepper, canola, tomato, and maize [15, $27,40,42,44]$. The reduction of total dry weight in the salt-sensitive cultivar (IR29) and the moderately salt-tolerant cultivar (FL478) was recovered by the inoculation with B. linens RS16 even at longer salt stress exposure similar to another reported results [27]. In our study, inoculation of rice plants with $B$. linens RS16 improved the salt stress effects on total dry weight in both cultivars. But the degree of improvement was significantly higher in the salt-sensitive cultivar (IR29) compared to the moderately salt-tolerant cultivar (FL478). The inoculation of $B$. linens RS16 enhanced the total plant dry weight for both control and salt stressed plants (Fig. 2).

\section{The effect of bacterial inoculation on total proline accumulation in plants after imposing salt stress and its correlation with total dry weight of plants}

Proline accumulation in the whole plant was also estimated on the basis of total dry weight. Although plant species can differ considerably in the amount of proline that accumulates upon salt stress, there is no clear relationship between the ability to accumulate proline on salt stress tolerance [32]. It has been reported that high accumulation of proline under salt stress increased higher green leaf area in rice plant [45]. In addition, an increased proline accumulation in the whole plant and total soluble sugar in the PGPR-treated wheat plants significantly contributed to their osmotolerance [46]. Proline accumulation was found to be higher in the roots and leaves of the salt-tolerant cultivar Giza 182 compared to the salt-susceptible variety Sakha 105 [8]. In our case, proline accumulation in the whole plant was higher in the moderately salt-tolerant cultivar (FL478) compared to the salt-sensitive cultivar (IR29) when exposed to $50 \mathrm{mM}$ and $150 \mathrm{mM}$ of salt stress at 10 days. This finding is in agreement with the recent results was reported [8].

On the other hand, inoculation of B. linens RS16 significantly increased the proline accumulation of the whole plant in the salt-sensitive cultivar (IR29) compared to the non-inoculated control plants. But, the moderately salttolerant cultivar (FL478) had shown higher accumulation of proline compared to the salt-sensitive counterpart. There were no significant changes of proline accumulation in the moderately salt-tolerant cultivar (FL478) with or without inoculation. These results indicated that bacterial inoculation was more effective in the salt-sensitive cultivar (IR29) than the moderately salt-tolerant cultivar (FL478). This might be due to the fact that bacterial inoculation had significantly increased the total dry weight of the salt-sensitive cultivar (IR29). Similarly, it has been reported that, the increase in proline accumulation in maize plants was positively correlated to plant dry weight [47]. Another study was also reported that [42], maize plant biomass was negatively correlated $\left(\mathrm{R}^{2}=0.84^{* * * *}\right.$ to $\left.0.88^{* * * *}\right)$ with $\mathrm{Na}^{+}$accumulation, but positively correlated $\left(\mathrm{R}^{2}=0.59^{*}\right.$ to $\left.0.58^{*}\right)$ with $\mathrm{K}^{+}$concentration when plants were inoculated with plant growth promoting rhizobacteria. These reports also corroborate with the results in this study with a positive correlation between proline accumulation and plant biomass. Hence, the increase in total proline accumulation by the $B$. linens RS16 inoculation had resulted in overall increase in plant growth under salt stress conditions for both the rice cultivars. Further, the correlation between total dry weight and proline accumulation in the salt-sensitive cultivar (IR29) and the moderately salt-tolerant cultivar (FL478) also revealed significant positive correlation, but in the case of the salt-sensitive cultivar (IR29), it was highly correlated $\left(0.61^{* * *}\right)$. These results indicated that inoculation of $B$. linens RS16 had increased total dry weight significantly with the increased amount of proline accumulation in the salt-sensitive cultivar (IR29) compared to the moderately salt-tolerant cultivar (FL478) to alleviate salt stress.

In agreement with these results, increased amount of proline has been reported in soybean plants grown under saline conditions upon inoculation with PGPR strains that alleviated salt stress and improved growth [48]. Root colonization with PGPRs in the wheat plant [49] with Azospirillum as a PGPR in plant [50] could also accumulate higher amount of proline as an osmoprotectant. Our results indicated a more effective salt stress mitigation by B. linens RS16 in the salt-sensitive cultivar (IR29) compared to the moderately salt-tolerant cultivar (FL478) at 3 and 10 days under salt stress conditions.

\section{The effect of bacterial inoculation on total glycine betaine accumulation in plants after imposing salt stress and its correlation with total dry weight of plants}

Glycine betaine is one of the quaternary ammonium compounds which is accumulated at high concentrations in many plant species and therefore, have been proposed to have roles in tolerance under saline environments [51, 52]. Accumulation of glycine betaine in the whole plant under stress conditions can be controversial. It has been reported that [53], under saline condition, rice plant was observed to increase the amount of glycine betaine in the tolerant and sensitive plants compared to the controls. During salt stress they found that glycine betaine accumulation was 1.3 times more in salt-tolerant line compared to the salt-sensitive line, which corroborates to the 
present study. In this study, glycine betaine accumulation in the whole plant was higher in the moderately salt-tolerant cultivar (FL478) compared to the salt-sensitive cultivar (IR29) after imposing $50 \mathrm{mM}$ and $150 \mathrm{mM}$ of salt stress. It might be a case of pigment stabilization because the relative water content in the rice plant is generally reduced due to salinity, which causes water oxidation in photosynthetic system II [54], and the accumulation of glycine betaine is helpful for stabilizing photosynthetic activity [52].

On the other hand, inoculation of B. linens RS16 showed a significantly increased glycine betaine accumulation in the salt-sensitive cultivar (IR29) compared to non-inoculated control. Still, it was lower than the moderately salt-tolerant cultivar (FL478). There was no significant change of glycine betaine accumulation in the moderately salt-tolerant cultivar (FL478) with or without inoculation. These findings indicated that bacterial inoculation was more effective in the salt-sensitive cultivar (IR29) than the moderately salt-tolerant cultivar (FL478). It might be the case of the significant increase of total dry weight in the salt-sensitive cultivar (IR29). These results clearly indicate that glycine betaine accumulation varied with the degree of salt tolerance of the different rice cultivars. It has been reported that plant growth promoting rhizobacteria can stimulate glycine betaine accumulation and increase significantly under salt stress conditions [55]. They reported that under saline condition the overall expression of glycine betaine was lower in rice plant, but PGPRs help in the enhancement of glycine betaine accumulation in leaves. This increased amount of glycine betaine may contribute to the increase of the $\mathrm{Na}^{+}$flux from the cytoplasm to the vacuole and also known to modify the membrane potentiality. In addition to osmoregulation, glycine betaine stabilizes the oxygenevolving activity of photosystem-II protein complex ultimately improve the plant growth parameters by protecting against dissociation of regulatory extrinsic proteins [55]. Similarly, our result also indicated that plants inoculated with $B$. linens RS16 were shown higher plant biomass even under $150 \mathrm{mM}$ salinity condition with increased amount of glycine betaine which helps to overcome the deleterious effects of salt stress in both cultivars (Figs. 2 and 5). However, the total dry weight and the total glycine betaine accumulation in both cultivars showed no significant correlation. Total dry weight decreased with an increased amount of glycine betaine accumulation in the whole plant, but there was no significant amount of reduction. It might be the case of non-significant accumulation of glycine betaine in the moderately salt-tolerant cultivar (FL478). Supporting evidence of these results showed that high level of glycine betaine accumulation is not necessarily correlated with high degree of salt tolerance, but the additional accumulation of chloroplastic glycine betaine is likely to further raise the level stability of photosynthetic machinery [56]. Further correlation between the total dry weight and the glycine betaine accumulation with individual cultivars showed the same. Many studies reported that glycine betaine contributed to mitigate toxic effect rather than improving plants' growth [57]. They reported that in rice seedlings, tolerance to salt stress is enhanced by the accumulation of glycine betaine even if levels of glycine betaine are lower in the chloroplast [57]. Our results showed that inoculation of $B$. linens RS16 did not significantly increase the accumulation of glycine betaine in both cultivars except when the salt-sensitive cultivar (IR29) was treated with salt stress for 10 days. This might be due to the negative correlation between the total dry weight and the total glycine betaine accumulation in both cultivars except when the salt-sensitive cultivar experiences high salinity stress for long period of time. In agreement to this results, it was reported that glycine betaine with plant adaptation to salt imposition has a major role in the salt tolerance of the halophyte Plantago crassifolia under salt stress conditions rather than improving plants' growth [58].

In conclusion, salt stress had a significant effect on both proline and glycine betaine accumulation in rice. The salt-tolerant cultivar (FL478) had recorded significantly higher accumulation of these osmolytes compared to the salt-sensitive cultivar (IR29). The bacterial inoculation resulted in a significant increase in accumulation of proline and glycine betaine in the salt-sensitive cultivar only after 10 days of salt stress exposure. On the other hand, the inoculation did not have any significant effect on the proline and glycine betaine accumulation to the salt-tolerant cultivar. Hence, the accumulation of proline and glycine betaine in plants depend on salt concentrations, exposure time to salt stress as well as genotypic variations. The variation in the accumulation of these compatible solutes in different cultivars in response to salt stress is closely related to bacterial inoculation.

\section{Supplementary Information}

The online version contains supplementary material available at https://doi. org/10.1186/s13765-021-00638-x.

Additional file 1: Table S1. Results of statistical analysis on the shoot length in the salt-sensitive cultivar (IR29) and the moderately salt-tolerant cultivar (FL478) under 0, 50 and $150 \mathrm{mM}$ salt stress. Different letters (A, B, C) indicated significant differences among the treatments at each salt levels. Table S2. Results of statistical analysis on the total length in the saltsensitive cultivar (IR29) and the moderately salt-tolerant cultivar (FL478) under 0, 50 and $150 \mathrm{mM}$ salt stress. Different letters (A, B, C) indicated significant differences among the treatments at each salt levels. Table S3. Results of statistical analysis on the total dry weight of the salt-sensitive cultivar (IR29) and moderately salt-tolerant cultivar (FL478) under 0, 50 and $150 \mathrm{mM}$ salt stress. Different letters $(A, B, C)$ indicated significant differences among the treatments at each salt levels. Figure S1. Correlation 
between total dry weight and total proline accumulation of (A) saltsensitive cultivar (IR29), (B) moderately salt-tolerant cultivar (FL478), and correlation between total dry weight and total glycine betaine accumulation of (C) salt-sensitive cultivar (IR29) and (D) moderately salt-tolerant cultivar (FL478) under salt stress conditions. A total of 36 observation data (bacteria inoculated and non-inoculated) of each cultivar at 3 and 10 days after salt stress was considered for analysis. ${ }^{* * *}$ signifies correlation that is significant at $p<0.001$ and ${ }^{* *}$ at $p<0.01$

\section{Acknowledgements}

\section{Not applicable.}

\section{Authors' contributions}

SA and TS: designed the experiments; SA: conducted the experiments; ARC and JC: Assisted in experiments; SA and TYH: Analysis of data; SA, ARC, DIW and TS: wrote the manuscript; ARC, DIW and TS: critical revision of manuscript. All authors read and approved the final manuscript.

\section{Funding}

This work was supported by the Basic Science Research Program, National Research Foundation of Korea (NRF), Ministry of Education, Science and Technology [2021R1A2C1006608], Republic of Korea.

\section{Availability of data and materials}

The datasets used and/or analyzed during the current study are included in this published article and any additional information are available from the corresponding author on reasonable request.

\section{Declarations}

\section{Competing interests}

The authors declare no competing interests.

\section{Author details}

${ }^{1}$ Present Address: Department of Environmental and Biological Chemistry, College of Agriculture, Life and Environment Sciences, Chungbuk National University, Chungbuk 28644 Cheongju, Republic of Korea. ${ }^{2}$ Present Address: Department of Information and Statistics, Chungbuk National University, Cheongju, Republic of Korea. ${ }^{3}$ College of Agriculture, Fisheries and Forestry, Romblon State University, Romblon, Philippines. ${ }^{4}$ Present Address: Department of Agricultural Extension (DAE), Ministry of Agriculture (MOA), Khamarbari, Dhaka, Bangladesh. ${ }^{5}$ The Korean Academy of Science and Technology, 13630 Seongnam, Republic of Korea. ${ }^{6}$ Present Address: Bio-Evaluation Center, Korea Research Institute of Bioscience and Biotechnology, 28116 Cheongju, Republic of Korea.

Received: 29 July 2021 Accepted: 28 August 2021

Published online: 16 September 2021

\section{References}

1. Endo T, Yamamoto S, Larrinaga JA, Fujiyama H, Honna T (2011) Status and causes of soil salinization of irrigated agricultural lands in southern Baja California. Mexico Appl Environ Soil Sci. https://doi.org/10.1155/2011/ 873625

2. Arora S (2017) Diagnostic properties and constraints of salt-affected soils. In: Arora S, Singh AK, Singh YP (eds) Bioremediation of salt affected soils: an Indian perspective. Springer, Cham, pp 41-52. https://doi.org/10. 1007/978-3-319-48257-6_2

3. Qadir M, Quillérou E, Nangia V, Murtaza G, Singh M, Thomas RJ, Drechsel P, Noble AD (2014) Economics of salt-induced land degradation and restoration. Nat Resour Forum 38(4):282-295. https://doi.org/10.1111/ 1477-8947.12054

4. Al-Enazy AA, Al-Barakah F, Al-Oud S, Usman A (2018) Effect of phosphogypsum application and bacteria co-inoculation on biochemical properties and nutrient availability to maize plants in a saline soil. Arch Agron Soil Sci 64:1394-1406. https://doi.org/10.1080/03650340.2018.1437909
5. Munns R, Tester M (2008) Mechanisms of salinity tolerance. Annu Rev Plant Biol 59:651-681. https://doi.org/10.1146/annurev.arplant.59.032607. 092911

6. Nxele X, Klein A, Ndimba B (2017) Drought and salinity stress alters ROS accumulation, water retention, and osmolyte content in sorghum plants. S Afr J Bot 108:261-266. https://doi.org/10.1016/j.sajb.2016.11.003

7. Singh M, Kumar J, Singh S, Singh VP, Prasad SM (2015) Roles of osmoprotectants in improving salinity and drought tolerance in plants: a review. Rev Environ Sci Bio-Technol 14:407-426. https://doi.org/10.1007/ s11157-015-9372-8

8. Abdelaziz M, Xuan T, Mekawy A, Wang H, Khanh T (2018) Relationship of salinity tolerance to $\mathrm{Na}^{+}$exclusion, proline accumulation, and antioxidant enzyme activity in rice seedlings. Agriculture 8:166. https://doi.org/10. 3390/agriculture8110166

9. Salinas R, Sánchez E, Ruíz J, Lao M, Romero L (2013) Proline, betaine, and choline responses to different phosphorus levels in green bean. Commun Soil Sci Plant Anal 44:465-472. https://doi.org/10.1080/00103624. 2013.744146

10. Xu Z, Sun M, Jiang X, Sun H, Dang X, Cong H, Qiao F (2018) Glycinebetaine biosynthesis in response to osmotic stress depends on jasmonate signaling in watermelon suspension cells. Front Plant Sci 9:1469-1469. https://doi.org/10.3389/fpls.2018.01469

11. You L, Song Q, Wu Y, Li S, Jiang C, Chang L, Yang X, Zhang J (2019) Accumulation of glycine betaine in transplastomic potato plants expressing choline oxidase confers improved drought tolerance. Planta 249(6):19631975. https://doi.org/10.1007/s00425-019-03132-3

12. Chanratana M, Han GH, Melvin Joe M, Roy Choudhury A, Sundaram S, Halim MA, Sa T (2018) Evaluation of chitosan and alginate immobilized Methylobacterium oryzae CBMB20 on tomato plant growth. Arch Agron Soil Sci 64:1489-1502. https://doi.org/10.1080/03650340.2018.1440390

13. Chatterjee P, Samaddar S, Anandham R, Kang Y, Kim K, Selvakumar G, Sa T (2017) Beneficial soil bacterium Pseudomonas frederiksbergensis OS261 augments salt tolerance and promotes red pepper plant growth. Front Plant Sci 8:705. https://doi.org/10.3389/fpls.2017.00705

14. Siddikee MA, Glick BR, Chauhan PS, Yim W, Sa T (2011) Enhancement of growth and salt tolerance of red pepper seedlings (Capsicum annuum L.) by regulating stress ethylene synthesis with halotolerant bacteria containing 1-aminocyclopropane-1-carboxylic acid deaminase activity. Plant Physiol Biochem 49:427-434. https://doi.org/10.1016/j.plaphy.2011. 01.015

15. Samaddar S, Chatterjee P, Choudhury AR, Ahmed S, Sa T (2019) Interactions between Pseudomonas spp. and their role in improving the red pepper plant growth under salinity stress. Microbiol Res 219:66-73. https://doi.org/10.1016/j.micres.2018.11.005

16. Chatterjee P, Kanagendran A, Samaddar S, Pazouki L, Sa T-M, Niinemets Ü (2019) Methylobacterium oryzae CBMB20 influences photosynthetic traits, volatile emission and ethylene metabolism in Oryza sativa genotypes grown in salt stress conditions. Planta 249(6):1903-1919. https://doi.org/ 10.1007/s00425-019-03139-w

17. Islam MR, Sultana T, Joe MM, Yim W, Cho JC, Sa T (2013) Nitrogen-fixing bacteria with multiple plant growth-promoting activities enhance growth of tomato and red pepper. J Basic Microbiol 53:1004-1015. https://doi.org/10.1002/jobm.201200141

18. Poonguzhali S, Madhaiyan M, Yim W-J, Kim K-A, Sa T-M (2008) Colonization pattern of plant root and leaf surfaces visualized by use of green-fluorescent-marked strain of Methylobacterium suomiense and its persistence in rhizosphere. App Microbiol Biotechnol 78:1033-1043. https://doi.org/10.1007/s00253-008-1398-1

19. Siddikee MA, Chauhan P, Anandham R, Han G-H, Sa T (2010) Isolation, characterization, and use for plant growth promotion under salt stress, of ACC deaminase-producing halotolerant bacteria derived from coastal soil. J Microbiol Biotechnol 20:1577-1584. https://doi.org/10.4014/jmb. 1007.07011

20. Chatterjee P, Kanagendran A, Samaddar S, Pazouki L, Sa T-M, Niinemets Ü (2018) Inoculation of Brevibacterium linens RS16 in Oryza sativa genotypes enhanced salinity resistance: impacts on photosynthetic traits and foliar volatile emissions. Sci Total Environ 645:721-732. https://doi.org/10. 1016/.scitotenv.2018.07.187

21. Zeng L, Shannon MC, Lesch SM (2001) Timing of salinity stress affects rice growth and yield components. Agric Water Manage 48:191-206. https:// doi.org/10.1016/S0378-3774(00)00146-3 
22. Walitang DI, Kim K, Madhaiyan M, Kim YK, Kang Y, Sa T (2017) Characterizing endophytic competence and plant growth promotion of bacterial endophytes inhabiting the seed endosphere of Rice. BMC Microbiol 17:209. https://doi.org/10.1186/s12866-017-1117-0

23. Subramanian P, Krishnamoorthy R, Chanratana M, Kim K, Sa T (2015) Expression of an exogenous 1-aminocyclopropane-1-carboxylate deaminase gene in psychrotolerant bacteria modulates ethylene metabolism and cold induced genes in tomato under chilling stress. Plant Physiol Biochem 89:18-23. https://doi.org/10.1016/j.plaphy.2015.02.003

24. Harrington S (2010) Greenhouse procedures manual: growing rice under controlled conditions. Cornell University, Ithaca

25. Madhaiyan M, Poonguzhali S, Kang B-G, Lee Y-J, Chung J-B, Sa T-M (2010) Effect of co-inoculation of methylotrophic Methylobacterium oryzae with Azospirillum brasilense and Burkholderia pyrrocinia on the growth and nutrient uptake of tomato, red pepper and rice. Plant Soil 328:71-82. https://doi. org/10.1007/s11104-009-0083-1

26. Vaidyanathan $H$, Sivakumar $P$, Chakrabarty $R$, Thomas $G$ (2003) Scavenging of reactive oxygen species in $\mathrm{NaCl}$-stressed rice (Oryza sativa $\mathrm{L}$.) — differential response in salt-tolerant and sensitive varieties. Plant Sci 165:1411-1418. https://doi.org/10.1016/.jplantsci.2003.08.005

27. Chatterjee P, Samaddar S, Niinemets Ü, Sa T-M (2018) Brevibacterium linens RS16 confers salt tolerance to Oryza sativa genotypes by regulating antioxidant defense and $\mathrm{H}^{+}$ATPase activity. Microbiol Res 215(2018):89-101. https://doi.org/10.1016/.jmicres.2018.06.007

28. Bates L, Waldren R, Teare I (1973) Rapid determination of free proline for water-stress studies. Plant Soil 39:205-207. https://doi.org/10.1007/BF000 18060

29. Grieve C, Grattan S (1983) Rapid assay for determination of water soluble quaternary ammonium compounds. Plant Soil 70:303-307. https://doi.org/ 10.1007/BF02374789

30. Roy SJ, Negrão S, Tester M (2014) Salt resistant crop plants. Curr Opin Biotechnol 26:115-124. https://doi.org/10.1016/j.copbio.2013.12.004

31. Kohler J, Hernández JA, Caravaca F, Roldán A (2009) Induction of antioxidant enzymes is involved in the greater effectiveness of a PGPR versus AM fungi with respect to increasing the tolerance of lettuce to severe salt stress. Environ Exp Bot 65:245-252. https://doi.org/10.1016/j.envexpbot.2008.09. 008

32. Kanawapee N, Sanitchon J, Lontom W, Threerakulpisut P (2012) Evaluation of salt tolerance at the seedling stage in rice genotypes by growth performance, ion accumulation, proline and chlorophyll content. Plant Soil 358:235-249. https://doi.org/10.1007/s11104-012-1179-6

33. Ali MN, Ghosh B, Gantait S, Chakraborty S (2014) Selection of rice genotypes for salinity tolerance through morpho-biochemical assessment. Rice Sci 21:288-298. https://doi.org/10.1016/S1672-6308(13)60189-4.s

34. Acosta-Motos J, Ortuño M, Bernal-Vicente A, Diaz-Vivancos P, SanchezBlanco M, Hernandez J (2017) Plant responses to salt stress: adaptive mechanisms. Agronomy 7:18. https://doi.org/10.3390/agronomy7010018

35. Ma Y, Rajkumar M, Moreno A, Zhang C, Freitas H (2017) Serpentine endophytic bacterium Pseudomonas azotoformans ASS1 accelerates phytoremediation of soil metals under drought stress. Chemosphere 185(75):85. https://doi.org/10.1016/j.chemosphere.2017.06.135

36. Mayak S, Tirosh T, Glick BR (2004) Plant growth-promoting bacteria that confer resistance to water stress in tomatoes and peppers. Plant Sci 166(2):525-530. https://doi.org/10.1016/j.plantsci.2003.10.025

37. AbdElgawad H, Zinta G, Hegab MM, Pandey R, Asard H, Abuelsoud W (2016) High salinity induces different oxidative stress and antioxidant responses in maize seedlings organs. Front Plant Sci 7:276. https://doi.org/10.3389/fpls. 2016.00276

38. Vurukonda SS, Vardharajula S, Shrivastava M, Sk ZA (2016) Enhancement of drought stress tolerance in crops by plant growth promoting rhizobacteria. Microbiol Res 184:13-24. https://doi.org/10.1016/j.micres.2015.12.003

39. Feng W, Lindner H, Robbins NE, Dinneny JR (2016) Growing out of stress: the role of cell- and organ-scale growth control in plant water-stress responses. Plant Cell 28:1769-1782. https://doi.org/10.1105/tpc.16.00182

40. Siddikee MA, Sundaram S, Chandrasekaran M, Kim K, Selvakumar G, Sa T (2015) Halotolerant bacteria with ACC deaminase activity alleviate salt stress effect in canola seed germination. J Korean Soc Appl Biol Chem 58:237-241. https://doi.org/10.1007/s13765-015-0025-y

41. Krishnamoorthy R, Kim K, Subramanian P, Senthilkumar M, Anandham R, SaT (2016) Arbuscular mycorrhizal fungi and associated bacteria isolated from salt-affected soil enhances the tolerance of maize to salinity in coastal reclamation soil. Agric Ecosyst Environ 231:233-239. https://doi.org/10. 1016/j.agee.2016.05.037

42. Rojas-Tapias D, Moreno-Galván A, Pardo-Díaz S, Obando M, Rivera D, Bonilla R (2012) Effect of inoculation with plant growth-promoting bacteria (PGPB) on amelioration of saline stress in maize (Zea mays). App Soil Eco 61:264-272. https://doi.org/10.1016/j.apsoil.2012.01.006

43. Etesami H, Beattie G (2018) Mining halophytes for plant growth-promoting halotolerant bacteria to enhance the salinity tolerance of non-halophytic crops. Front Microbiol 9:148. https://doi.org/10.3389/fmicb.2018.00148

44. Nabti E, Schmid M, Hartmann A (2015) Application of halotolerant bacteria to restore plant growth under salt stress. In: Maheshwari DK, Saraf M (eds) Halophiles. Springer, Cham, pp 235-259. https://doi.org/10.1007/ 978-3-319-14595-2_9

45. Pongprayoon W, Cha-um S, Pichakum A, Kirdmanee C (2008) Proline profiles in aromatic rice cultivars photoautotrophically grown in responses to salt stress. Int J Bot 4:276-282

46. Upadhyay SK, Singh JS, Saxena AK, Singh DP (2012) Impact of PGPR inoculation on growth and antioxidant status of wheat under saline conditions. Plant Biol 14:605-611. https://doi.org/10.1111/j.1438-8677.2011.00533.x

47. Kravić N, Marković K, Anđelković V, Šukalović VH-T, BabićV, Vuletić M (2013) Growth, proline accumulation and peroxidase activity in maize seedlings under osmotic stress. Acta Physiol Plant 35:233-239. https://doi.org/10. 1007/s11738-012-1068-x

48. Han H, Lee K (2005) Physiological responses of soybean-inoculation of Bradyrhizobium japonicum with PGPR in saline soil conditions. Res J Agric Biol Sci 1:216-221

49. Zarea M, Hajinia S, Karimi N, Goltapeh EM, Rejali F, Varma A (2012) Effect of Piriformospora indica and Azospirillum strains from saline or non-saline soil on mitigation of the effects of $\mathrm{NaCl}$. Soil Biol Biochem 45:139-146. https:// doi.org/10.1016/j.soilbio.2011.11.006

50. Casanovas EM, Barassi CA, Andrade FH, Sueldo RJ (2003) Azospirilluminoculated maize plant responses to irrigation restraints imposed during flowering. Cereal Res Commun 31(3):395-402

51. Chen TH, Murata N (2002) Enhancement of tolerance of abiotic stress by metabolic engineering of betaines and other compatible solutes. Curr Opin Plant Biol 5:250-257. https://doi.org/10.1016/S1369-5266(02)00255-8

52. Chen TH, Murata N (2008) Glycinebetaine: an effective protectant against abiotic stress in plants. Trends Plant Sci 13:499-505. https://doi.org/10. 1016/j.tplants.2008.06.007

53. Cha-um S, Supaibulwatana K, Kirdmanee C (2007) Glycinebetaine accumulation, physiological characterizations and growth efficiency in salt-tolerant and salt-sensitive lines of indica rice (Oryza sativa L. ssp. indica) in response to salt stress. J Agron Crop Sci 193(3):157-166. https://doi.org/10.1111/j. 1439037X.2007.00251.X

54. Tian F, Wang W, Liang C, Wang X, Wang G, Wang W (2017) Overaccumulation of glycine betaine makes the function of the thylakoid membrane better in wheat under salt stress. Crop J 5(1):73-82. https://doi.org/10.1016/j. cj.2016.05.008

55. Jha Y, Subramanian RB, Patel S (2011) Combination of endophytic and rhizospheric plant growth promoting rhizobacteria in Oryza sativa shows higher accumulation of osmoprotectant against saline stress. Acta Physiol Plant 33:797-802. https://doi.org/10.1007/s11738-010-0604-9

56. Park EJ, Jeknic Z, Pino MT, Murata N, Chen TH (2007) Glycinebetaine accumulation is more effective in chloroplasts than in the cytosol for protecting transgenic tomato plants against abiotic stress. Plant Cell Environ 30:994-1005. https://doi.org/10.1111/j.1365-3040.2007.01694.x

57. Sakamoto A, Murata N (1998) Metabolic engineering of rice leading to biosynthesis of glycinebetaine and tolerance to salt and cold. Plant Mol Biol 38:1011-1019. https://doi.org/10.1023/A:1006095015717

58. Pardo-Domènech LL, Tifrea A, Grigore MN, Boscaiu M, Vicente O (2016) Proline and glycine betaine accumulation in two succulent halophytes under natural and experimental conditions. Plant Biosyst 150:904-915. https://doi. org/10.1080/11263504.2014.990943

\section{Publisher's Note}

Springer Nature remains neutral with regard to jurisdictional claims in published maps and institutional affiliations. 